McNaught, K. A., Morris, J. S. and McLaughlin, M. (2020) Preliminary assessment of serum clusterin as a potential biomarker for canine lymphoma. Veterinary and Comparative Oncology, 18(3), pp. 292-302. (doi: 10.1111/vco.12550).

There may be differences between this version and the published version. You are advised to consult the publisher's version if you wish to cite from it.

This is the peer reviewed version of the following article:

McNaught, K. A., Morris, J. S. and McLaughlin, M. (2020) Preliminary assessment of serum clusterin as a potential biomarker for canine lymphoma. Veterinary and Comparative Oncology, 18(3), pp. 292-302, which has been published in final form at $10.1111 / \mathrm{vco.12550}$. This article may be used for non-commercial purposes in accordance with Wiley Terms and Conditions for Self-Archiving.

\title{
http://eprints.gla.ac.uk/204308/
}

Deposited on: 28 November 2019

Enlighten - Research publications by members of the University of Glasgow http://eprints.gla.ac.uk 


\section{Preliminary assessment of serum clusterin as a potential biomarker for canine lymphoma.}

Short informative title: serum clusterin as a biomarker in canine lymphoma

Short running title: serum clusterin in canine lymphoma

Authors: Katie A. McNaught ${ }^{1}$, Joanna S. Morris ${ }^{1}$, Mark McLaughlin ${ }^{2}$

${ }^{1}$ Small Animal Hospital, School of Veterinary Medicine, College of Medical Veterinary and Life Sciences, University of Glasgow, UK.

${ }^{2}$ Department of Veterinary Science and Education, School of Veterinary Medicine, College of Medical Veterinary and Life Sciences, University of Glasgow, UK.

\section{Acknowledgements}

The authors gratefully acknowledge the Pet Blood Bank ${ }^{\mathrm{UK}}$ for supplying the control samples.

This work was supported by the University of Glasgow, School of Veterinary Medicine Vet Fund.

Word Count: 3275

Abstract word count: 155

Tables: 3

Figures: 6

$\underline{\text { Data availability }}$

The data that support the findings of this study are available from the corresponding author upon reasonable request.

No conflicts of interest to declare. 


\section{Abstract}

Clusterin (CLU), also known as apolipoprotein J, is a widely expressed, heterodimeric, glycoprotein, important in tumourigenesis, apoptosis, and immunoregulation. In humans, clusterin expression has been associated with anaplastic large cell and Hodgkin's lymphoma. In this study, serum clusterin levels in dogs with multicentric lymphoma (MLSA) were compared to healthy control dogs, using both western blot and ELISA. Western blot confirmed the presence of clusterin in dog sera at the predicted molecular weight and the relative levels detected correlated with the levels detected by ELISA. Clusterin level analysis by ELISA found treatment naïve dogs with MLSA had a significantly $(p<0.001)$ lower serum clusterin level compared to healthy controls. However, there was no significant difference between MLSA dogs prior to treatment and in complete remission. The wide variation in serum CLU levels may limit its potential as a single candidate biomarker for MLSA, although any prognostic predictive value of serum CLU concentrations has yet to be assessed.

Keywords: Biomarkers, CLU protein, Clusterin, Dogs, Lymphoma.

\section{$\underline{\text { Introduction }}$}

Lymphoma is a malignant neoplasm which arises from a clonal proliferation of lymphoreticular cells. ${ }^{1}$ It is the most common canine haematopoietic neoplasm, ${ }^{1,2}$ accounting for $7-24 \%$ of all canine malignancies. ${ }^{3-5}$ Multiple blood $^{6-12}$ and tissue $e^{13,14}$ biomarkers have been investigated regarding potential prognostic or diagnostic use in canine lymphoma, however no single marker has proved more valuable than established parameters e.g. stage, substage, immunophenotype.

Based on observations from human studies, one potential candidate biomarker for haematopoietic mediated disorders is the protein clusterin. Initially identified in the fluid of ram rete testes, the clusterin (CLU) protein was found to elicit aggregation, or clustering, of a variety of different cells. ${ }^{15}$ The CLU gene is unique in the genome and well conserved, with the structure of the clusterin protein showing little variation between species. ${ }^{16-18}$ The CLU gene codes for at least three different protein forms; nuclear, cytoplasmic and secretory, each with different biological functions. ${ }^{19,20}$ Secretory CLU, formed in the Golgi apparatus, enters the extracellular compartment as a glycosylated protein. ${ }^{21}$ This extracellular form of the CLU protein, also known 
as apolipoprotein J, is a heterodimeric, glycoprotein composed of an $\alpha$ and $\beta$ subunit ${ }^{20,22}$ comigrating at approximately $37 \mathrm{kDa}$ by SDS-PAGE.

From the extracellular compartment CLU binds to a number of serum proteins including albumin ${ }^{23}$ and complement factors. CLU is heavily glycosylated, a feature which can affect both the nature of the protein itself, and its binding properties. Expressed in virtually every body tissue and fluid, ${ }^{21,24-27}$ CLU has been linked to multiple biological processes important for tumourigenesis; including apoptosis, tissue remodelling, membrane recycling, cell cycle regulation and immune system regulation. ${ }^{18,24,27-29}$ Regulated by cytokines and growth factors, increased CLU gene expression is also seen in response to physiological stress. ${ }^{24,25,28}$ Dysregulation of CLU, in both tissue and serum, has been associated with various human malignancies, $20,28,30,31$ including prostatic ${ }^{20,32}$ and mammary ${ }^{20,33-35}$ carcinoma, oesophageal squamous cell carcinoma, ${ }^{36}$ hepatocellular carcinoma ${ }^{37}$ and colorectal neoplasia, ${ }^{29,38}$ with CLU implicated both as a tumour suppressor ${ }^{39,40}$ and modifier of tumour promotion. ${ }^{39}$ These studies suggest that dysregulation of CLU expression, whether upregulated or downregulated, may have a key role in tumourigenesis.

Cytoplasmic expression of CLU has been positively identified, via immunohistochemistry (IHC), in cases of anaplastic large cell lymphoma..$^{31,41-43}$ Serum CLU expression was also upregulated in a subset of patients following treatment for Hodgkin's lymphoma.

Little has been reported regarding clusterin expression in canine malignancies. However, a previous study of the canine proteome, identified clusterin expression in the serum of a dog with high grade multicentric lymphoma, and the absence of clusterin expression in serum from two healthy controls. ${ }^{44}$ The objective of this study was to determine whether serum clusterin expression differed significantly between a cohort of dogs with untreated high grade multicentric lymphosarcoma (MLSA), those in complete remission (CR) after chemotherapy, and a healthy control population.

\section{Materials and Methods}

\section{$\underline{\text { Sample selection }}$}


Archived serum samples were searched to identify canine patients, who presented to the University of Glasgow Small Animal Hospital between 2013 and 2018, with a confirmed cytological and/or histopathological diagnosis of high grade MLSA. Retrospective analysis of the medical records was performed, to obtain information pertaining to signalment, WHO stage $(\mathrm{I}-\mathrm{V})$ and substage $(\mathrm{a}=\text { no clinical signs, } \mathrm{b}=\text { clinical signs })^{1,45}$ immunophenotype/genotype and clonality (from immunohistochemistry, flow cytometry or PARR analysis), treatment and response. Due to the retrospective nature, staging was not standardised, and stage migration could not be excluded.

After identifying suitable patients, MLSA samples were further categorised as either; 1) pre-treatment, taken at time of diagnosis, prior to any corticosteroid or chemotherapy treatment, or 2 ) in complete remission (CR), at week 4-6 of a (CHOP-based) chemotherapy protocol. Remission was determined, by a qualified veterinary surgeon experienced in veterinary oncology, using RECIST ${ }^{46}$ guidelines, by physical examination and lymph node palpation.

Exclusion criteria included severely haemolysed or lipaemic samples, concurrent infectious or systemic inflammatory disease and prior treatment. Samples from dogs who failed to achieve complete remission, and those who received alternative chemotherapy protocols were excluded from the CR sample pool.

Control serum samples were obtained from the Canine Pet Blood Bank, when collected for screening and monitoring purposes, at the time of blood donation. These were stored at $-20^{\circ} \mathrm{C}$ prior to transport and transported frozen to Glasgow.

The study was performed with full ethical approval from the Ethics and Welfare committee at the University of Glasgow, with owner consent obtained for the retention of spare serum. All serum samples were surplus blood, from samples collected for diagnostic and treatment purposes. Clotted serum samples were centrifuged at 9000 rpm for 3 minutes, serum was extracted and stored frozen. All serum samples were stored frozen, at $20^{\circ} \mathrm{C}$ prior to transfer for storage at $-80^{\circ} \mathrm{C}$, for analysis at a later date. 
All samples were selected, from the previously identified pool of suitable samples and controls, to generate three distinct sample groups. When creating these sample groups, preference was given to samples with shorter storage history, samples with larger sample volume, and samples with higher burden of disease (i.e. Stage III or above, as per the WHO staging system).

Sample group one consisted of 3 cohorts; dogs diagnosed with MLSA, pre-treatment $(A, n=12)$, unrelated dogs with MLSA, in CR (B, n=12) and healthy control dogs (C, $n=12)$, (Table 1).

Sample group two consisted of 2 cohorts; dogs diagnosed with MLSA, pre-treatment ( $n=18)$, and in CR ( $n=18)$, i.e. paired samples from the same individuals, (Table 2).

Sample group three consisted of 2 cohorts; dogs diagnosed with MLSA, pre-treatment $(n=18)$ and healthy control dogs ( $n=18)$, (Table 3). Samples for group three were intentionally selected to form age matched cohorts.

\section{Assessment of serum Clusterin level}

Two methods were employed to assess the level of serum clusterin: western blot was performed using a commercial anti-human antibody, predicted to have cross species reactivity with dog at $93 \%$, and previously validated $^{47,48}$ in the dog. Enzyme-linked immunosorbent assay (ELISA), was performed using a commercial (BioVendor Ltd) kit, previously validated using canine serum.

\section{Western blot analysis}

The presence of CLU in individual serum samples was initially evaluated via western blot analysis, as previously described. ${ }^{47,48}$ In brief, protein concentrations of the serum samples were determined using a bicinchoninic acid (BCA) protein assay system (Thermo Life Science Ltd, UK); 10ug aliquots of each sample were separated by sodium dodecyl sulfate-polyacrylamide gel electrophoresis (SDS - PAGE) using Criterion 26 well gels (BioRad Ltd, UK), and then transferred to nitrocellulose membranes using the iBlot system (Invitrogen, Thermo Fisher, UK). Samples from diseased and control dogs were loaded in alternate wells, with protein molecular weight standards (BioRad Ltd, UK) run in the first and last well of each gel. 
Following transfer, the membranes were blocked in $5 \%$ semi skimmed, milk solution with Tris- buffered saline containing $0.5 \%$ Tween 20 (T-TBS) and incubated overnight, at $4^{\circ} \mathrm{C}$, with a goat primary antibody against CLU (Antibody 104652, Abcam Ltd, UK), diluted 1:20,000. Membranes were then incubated with a horseradish peroxidase (HRP) conjugated secondary antibody (Abcam Ltd, UK), diluted to 1:10,000, at room temperature. Finally, an enhanced chemiluminescence reagent (Pierce ECL, Thermo Fisher, UK), allowed detection of the protein bands, with visualisation via radiographic film. Protein band density was quantified using Image-J software. $^{49}$

Three separate western blots were performed to compare the three cohorts in sample group one. Each individual cohort was directly compared to the others, via separate western blot analysis. Comparison of protein density between separate blots (i.e. inter-blot comparison) was not performed due to the inherent difficulties with variations in signal intensity between blots.

\section{ELISA}

CLU concentrations were measured using a sandwich enzyme immunoassay (BioVendor Ltd, UK) for quantitative measurement of canine clusterin. This assay was previously validated, by BioVendor, to have low within-run imprecision, with an intra-assay coefficient of variance $(n=8)$ of $4.3 \%$, and an acceptable betweenrun comparability, with inter-assay coefficients of variance $(n=8)$ of $6.2 \%$. A normal canine serum CLU concentration range has not yet been established.

Serum samples were diluted 1:2500 with dilution buffer [to facilitate the ELISA]. Each plate was loaded with samples, controls and protein standards in duplicate. The ELISA was run, as per manufacturer guidelines, using dilution and wash solutions provided. Following cessation of the colour change reaction, optical density of the samples was determined, using a microplate reader. A standard curve was generated, using results from the protein standards, allowing evaluation of sample clusterin concentrations.

\section{Statistical Analysis}

All analyses were performed using GraphPad Prism, version 5 for Windows (GraphPad Software, San Diego, California, USA) with statistical significance set at $p \leq 0.05$. The serum clusterin concentrations were analysed using parametric and non-parametric testing, depending on normality of data distribution, with student t- test, 
Mann-Whitney U test, Kruskal-Wallis, ANOVA and Wilcoxon signed-rank tests. Group characteristics were compared using Mann-Whitney U test, ANOVA, Chi squared and Fisher's exact tests.

\section{Results}

Antibody specificity was confirmed by western blot analysis prior to further investigations. Blots were incubated with and without the primary goat antibody against CLU (Antibody 104652, Abcam Ltd, UK) and the CLU protein band, visible at approximately $37 \mathrm{kDa}$, was only identified following incubation with the primary antibody (Figure 1). This was consistent with the secreted form of CLU, which is processed to generate two subunits, at approximately $37 \mathrm{kDa} .^{27,50,51}$

\section{$\underline{\text { Sample group one (unrelated samples) }}$}

Serum CLU concentrations were initially compared in 36 dogs by western blot analysis. Dogs were divided into 3 cohorts; those diagnosed with MLSA pre-treatment $(n=12)$, unrelated dogs with MLSA in CR $(n=12)$ and healthy control dogs $(n=12)$.

Signalment of the dogs with untreated and treated MLSA was similar (Table 1). Median age was not significantly different between pre-treated ( 8 years) and CR ( 7.5 years) cohorts and both pre-treatment $(n=9)$ and CR $(n=7)$ were predominantly male. Healthy control dogs were also predominantly male $(n=7)$ and there was no significant difference in sex or neuter status between all 3 cohorts (Chi-squared $p>0.05$ ). The median age ( 4 years) of the controls, however, was significantly younger than both MLSA cohorts (ANOVA, $p<0.05$ ). Stage of disease at initial presentation was higher in the pre-treatment samples, with significantly more stage $\mathrm{V}$ disease in comparison to those in $\mathrm{CR}$ (Fisher's exact, $\mathrm{p}<0.01$ ). There was no significant difference in substage between the two MLSA cohorts. Of the dogs for which immunophenotype was known there was no significant difference; the pre-treatment cohort had seven B-cell lymphoma and one T cell lymphoma, compared to ten B-cell lymphoma for those in CR (Fisher's exact, $p>0.05$ ).

Serum samples from each cohort (Control vs MLSA, Control vs CR and MLSA vs CR) were compared across three western blots (Figure 2). Intra-blot comparison of protein band density suggested a trend for a lower 
CLU level in dogs with MLSA in comparison to controls, however there was no statistically significant difference between the three cohorts ( $p>0.05$, student's t-test, Figure 3 ).

Measurement of serum CLU in the same 36 samples using a previously validated ELISA assay showed that median serum CLU concentration in dogs prior to treatment was 53.75ug/ml (range 15.9 - 101.1), compared to dogs in remission $67.0 \mathrm{ug} / \mathrm{ml}$ (49.3-116.8), and 93.60ug/l (70.1- 120.1) in healthy controls.

The median serum CLU concentrations differed significantly between the three groups, (Kruskal-Wallis $p<0.01$, Figure 4) and when individual groups were compared serum CLU was significantly lower $(p<0.05)$ in MLSA than controls. There was no significant difference however, in serum CLU levels in those dogs with MLSA, prior to treatment and in remission.

\section{Sample Group Two (paired samples)}

To make allowance for individual variation the group size was expanded and serum CLU concentrations were compared in a further 18 dogs. Paired samples were assessed from the same dog, at time of diagnosis (pretreatment) and again in CR. Signalment and MLSA phenotype were similar to that of the previously assessed samples (Table 2).

Median serum CLU concentration of samples from dogs prior to treatment [50.36ug/ml, range 36.08 -118.1] was not significantly different from median serum CLU at the time of CR [51.33ug/ml, range $33.98-141.1]$, (Wilcoxon signed-rank test, $p>0.05$, Figure 5). Subjective assessment of the data identified no consistent trends in serum CLU concentration within individuals; 7/18 (38.9\%) dogs had increased clusterin concentrations, while 7/18 (38.9\%) decreased and 4/18 (22.2\%) remained relatively static in remission.

\section{Sample Group Three (age matched samples)}

In the initial sample groups, there was a significant difference in age between dogs with MLSA and controls. To eliminate the bias of age on our results, an age matched sample and new control population were compared. Eighteen pre-treatment MLSA dogs (median age 6 years) were compared to 18 healthy controls (median age 5 years). The age, sex and neuter status were not significantly different between the two groups (Table 3). 
The median serum clusterin concentration in pre-treatment MLSA dogs [58.34ug/ml, range 30.48 - 137.4] was significantly lower than healthy controls [98.93ug/ml, range 73.18 - 141.0]. (Mann Whitney U, p<0.001, Figure 6).

\section{Discussion}

While the exact function of CLU is not precisely known, it is generally accepted that CLU acts as an extracellular chaperone protein, ${ }^{18}$ with functions similar to that of the small heat-shock proteins. ${ }^{52-54} \mathrm{CLU}$ expression increases in response to cellular stress, ${ }^{16,52-54}$ acting to stabilise and correct protein folding, or facilitate degradation of misfolded proteins and assist in the clearance of these proteins from extracellular spaces. 18,23,39,52-54 The chaperone function of secretory CLU is widely described, protecting cells from physical stress, neutralizing insult and facilitating clearance and disposal of toxic molecules. ${ }^{18,53}$ Therefore, changes in the regulation of expression and steady state levels of clusterin may occur as a consequence of a postulated role in tumourigenesis. Indeed, some studies in humans have suggested that down regulation and subsequent loss of CLU's chaperone function could play a role in tumourigenesis. ${ }^{20,28,55,56}$

In 2013, Atherton et al characterised the serum proteome of dogs with lymphoma, via serum protein electrophoresis and mass spectrometry. In this study multiple proteins, which were not identified in healthy dogs, were identified in dogs with lymphoma, although sample sizes were very small. In one dog with lymphoma, a clusterin precursor was identified in the alpha- 2 band of the proteome, leading to speculation that clusterin may have a role in canine lymphoma. ${ }^{44}$ In our study, the CLU protein was identified in all canine serum samples, using both western blot analysis and ELISA. Although there was marked variation in CLU levels between individuals, serum CLU in samples from dogs diagnosed with MLSA was consistently, significantly lower than that of a healthy control population.

Multiple studies investigating CLU in human epithelial neoplasia, ${ }^{29,32-34,57}$ show positive cytoplasmic or nuclear staining via immunohistochemistry (IHC) and some indicate increased serum CLU. ${ }^{36-38}$ Positive CLU staining via IHC has also been identified in a high percentage of anaplastic large cell lymphoma. ${ }^{31,41-43}$ However positive IHC staining in other forms of T-cell lymphoma and B-cell lymphoma is less common. ${ }^{31,41,43}$ Saffer et al. ${ }^{31}$ identified cytoplasmic CLU staining as positive in 35\% of lymphoid neoplasia assessed; but only present in a 
small subset (12\%) of diffuse large B cell lymphoma (DLBCL) cases. An unrelated in vitro study, ${ }^{58}$ also identified only a very low basal level of CLU via fluorescence microscopy and real-time PCR, in the Toledo DLBCL cell line compared to B lymphocytes from healthy human blood. While our current study population did not have histopathology diagnosis/classification, $\mathrm{DLBCL}$ is one of the most common lymphoma types seen in the canine population, accounting for up to $56 \%$ of MLSA diagnosis. ${ }^{1,59,60}$ Our study, identifying low CLU levels in MLSA serum, is consistent with human literature which reports low CLU levels in B cell lymphoma and T cell Iymphoma, with the exception of anaplastic large cell lymphoma. ${ }^{31,41,43}$

It has been shown in lab-based cell lines that doxorubicin treatment upregulates secretory clusterin isoforms. ${ }^{30,58}$ Despite the majority of our patients receiving doxorubicin as part of their chemotherapy protocol (week 4 of CHOP), this trend was not seen, and overall the median CLU level of dogs with MLSA in CR was still significantly lower than healthy controls. Our study showed no significant increase or decrease in serum CLU following chemotherapy. Individual serum CLU concentration following treatment was unpredictable; some dogs had increased clusterin concentrations, while others decreased or remained relatively static in remission. Similar variation in serum CLU has been reported in a small subset of human patients with Hodgkin's lymphoma following treatment with chemotherapy. ${ }^{30}$ To see whether CLU expression would alter with induction of remission, due to reduced burden of disease, our study samples from patients in remission were taken 4-6 weeks following the start of treatment, to allow time for CR to occur. Regardless, there was no significant increase or decrease in serum CLU found. It is possible that the small numbers in the study made the differences between pre-treatment samples and those in CR difficult to identify, or it may be that a single doxorubicin treatment in vivo is insufficient to cause the same alterations seen in vitro. From these preliminary findings it cannot be excluded that a relative change in individual CLU level could act as a marker for remission, relapse or response in canine lymphoma, following chemotherapy. Additional investigations, with larger numbers of patients and more statistical power may be of benefit to investigate this further. CLU has been implicated in a wide number of physiological and pathological processes, including tumourigenesis, regulation of cell death, and aging. ${ }^{24,28,53}$ In humans there is a relationship between CLU expression and age, with CLU expression increasing from gestation to adulthood, ${ }^{24,61,62}$ although significant individual variation exists. The CLU levels within our healthy control population did not vary significantly in relation to age, combining data from two ELISA plates, although this may in part be due to small sample size 
and overall narrow age range (1-7years). The possible impact of age on CLU levels prompted further evaluation in this study, using age matched MLSA and control samples. When cohorts were age matched there remained a highly significant difference in serum CLU levels, with serum CLU significantly lower in MLSA in comparison to controls.

Our study had several limitations and as a result, was very preliminary in nature. The study was partly retrospective, relying on patient records and stored samples. Samples frequently lacked histological confirmation of diagnosis and lymphoma subclassification and were therefore a heterogeneous group. In addition, since most cases were diagnosed cytologically, many of the samples were genotyped as B or T cell by PARR alone, rather than immunophenotyped by IHC or flow cytometry, although additional clinical information such as hypercalcaemia and mediastinal mass supported a diagnosis of T cell in 5 cases. With the small numbers in our study, it was not possible to say if serum CLU varied between B and T cell cases. If any cases in sample group one had been immunophenotyped incorrectly by using PARR alone, it may have affected the comparison between untreated cases and those unrelated cases in remission, although comparisons between MLSA dogs and controls would be unaffected. While every precaution was taken to ensure the integrity of the cases and samples selected, the history of the freeze/thaw cycles during storage were not always known. Additional studies with larger cohorts would be beneficial to increase statistical power, especially due to the wide individual variation in CLU levels. In addition, further investigations particularly to evaluate cytoplasmic CLU expression in canine malignant lymphoma tissue, concurrently, via IHC, may help clarify the relationship between circulating levels and tumour progression.

\section{Conclusion}

Serum CLU is significantly lower in patients with MLSA, although substantial individual variation exists. Results suggest that serum CLU may have limited benefit as a diagnostic biomarker, or marker of remission, although the potential prognostic value of CLU has not been investigated and would require more precise subclassification and immunophenotyping of samples. Additional studies with larger sample numbers are warranted, including further immunohistochemical evaluation of CLU in lymph nodes/tissue, to fully evaluate CLU expression in canine lymphoma. 


\section{$\underline{\text { References }}$}

1. Vail D, Pinkerton M, Young K. Canine Lymphoma and Lymphoid Leukaemias. In: Withrow and MacEwen's Small Animal Clinical Oncology. 5th ed. Elsevier; 2013:608-638.

2. Gavazza A, Sacchini F, Lubas G, Gugliucci B, Valori E. Clinical , laboratory, diagnostic and prognostic aspects of canine lymphoma : a retrospective study. Comp Clin Path. 2009;18:291-299.

3. Greenlee PG, Filippa DA, Quimby FW, et al. Lymphomas in Dogs. Cancer. 1990;66:480-490.

4. Fournel-Fleury C, Ponce F, Felman P, et al. Canine T-cell lymphomas: A morphological, immunological, and clinical study of 46 new cases. Vet Pathol. 2002;39(1):92-109.

5. Dobson JM, Samuel S, Milstein H, Rogers K, Wood JLN. Canine neoplasia in the UK : estimates of incidence rates from a population of insured dogs. J Small Anim Pract. 2002;43:240-246.

6. Merlo A, Rezende BCR, Franchini ML, Simões DMN, Lucas SR. Serum C-reactive protein concentrations in dogs with multicentric lymphoma undergoing chemotherapy. J Am Vet Med Assoc. 2007;230(4):522526.

7. Marconato L, Crispino G, Finotello R, Mazzotti S, Salerni F, Zini E. Serum lactate dehydrogenase activity in canine malignancies. Vet Comp Oncol. 2009;7(4):16-19. doi:10.1111/j.1476-5829.2009.00196.x

8. Von Euler H, Einarsson R, Olsson U, Lagerstedt A, Eriksson S. Serum Thymidine Kinase Activity in Dogs with Malignant Lymphoma: A Potent Marker for Prognosis and Monitoring the Disease. J Vet Intern Med. 2004;18:696-702.

9. Zanatta R, Abate O, Angelo AD, Miniscalco B, Mannelli A. Diagnostic and Prognostic Value of Serum Lactate Dehydrogenase ( LDH ) and LDH Isoenzymes in Canine Lymphoma. Vet Res Commun. 2003:449452.

10. Marconato L, Crispino G, Finotello R, Mazzotti S, Zini E. Clinical relevance of lactate dehydrogenase activity used to predict recurrence in dogs with lymphoma. J Am Vet Med Assoc. 2010;(236):969-974.

11. Elliott JW, Cripps P, Blackwood L. Thymidine kinase assay in canine lymphoma. Vet Comp Oncol. 2011;11(1):1-13.

12. Mischke R, Waterson M, Eckersall PD. Changes in C-reactive protein and haptoglobin in dogs with lymphatic neoplasia. Vet J. 2007;174:188-192. doi:10.1016/j.tvjl.2006.05.018

13. Rebhun RB, Lana SE, Ehrhart EJ, Charles JB, Thamm DH. Comparative Analysis of Survivin Expression in untreated and Relapsed Canine Lymphoma. J Vet Intern Med. 2008;22:989-995.

14. Wimmershoff J, Polkinghorne A, Grest P, Schade B, Marchal T. Immunohistochemical Detection of Survivin in Canine Lymphoma. J Comp Pathol. 2010;142(4):311-322. doi:10.1016/j.jcpa.2009.12.004

15. Fritz IB, Burdzy K, Sétchell B BO. Ram rete testis fluid contains a protein (clusterin) which influences cellcell interactions in vitro. Biol Reprod. 1983;28(5):1173-1188.

16. Michel D, Chatelain G, North S, Brun G. Stress-induced transcription of the clusterin/apoJ gene. Biochem J. 1997;328 ( Pt 1:45-50. doi:10.1042/bj3280045

17. Calero M, Tokuda T, Rostagno A, et al. Functional and structural properties of lipid-associated apolipoprotein J (clusterin). Biochem J. 1999;344 Pt 2:375-383. doi:10.1042/0264-6021:3440375

18. Wilson MR, Easterbrook-Smith SB. Clusterin is a secreted mammalian chaperone. Trends Biochem Sci. 2000;25(3):95-98. doi:10.1016/S0968-0004(99)01534-0

19. Rizzi F, Coletta M, Bettuzzi S. Clusterin (CLU): From One Gene and Two Transcripts to Many Proteins. Vol 104. 1st ed. Elsevier Inc.; 2009. doi:10.1016/S0065-230X(09)04002-0

20. Rizzi F, Bettuzzi S. The clusterin paradigm in prostate and breast carcinogenesis. 2010:1-17. doi:10.1677/ERC-09-0140

21. Bettuzzi S. Introduction. Adv Cancer Res. 2009;104(1):1-8. doi:10.1016/S0065-230X(09)04001-9

22. de Silva H, Harmony J, Stuart W, Gil C, Robbins J. Apolipoprotein J: structure and tissue distribution. Biochemistry. 1990;29(22):5380-5389.

23. Wyatt AR, Wilson MR. Identification of Human Plasma Proteins as Major Clients for the Extracellular Chaperone Clusterin *. J Biol Chem. 2010;285(6):3532-3539.

24. Trougakos IP, Gonos ES. Clusterin / Apolipoprotein J in human aging and cancer. 2002;34:1430-1448.

25. Trougakos IP, So A, Jansen B. Silencing Expression of the Clusterin / Apolipoprotein J Gene in Human Cancer Cells Using Small Interfering RNA Induces Spontaneous Apoptosis, Reduced Growth Ability, and Cell Sensitization to Genotoxic and Oxidative Stress Silencing Expression of the C. 2004:1834-1842.

26. Flach R, Cattaruzza M, Koch-brandt C. Clusterin gene expresison in apoptotic MDCK cells is dependent on the apoptosis-inducing stimulus. BBA, Biochim Biophys Acta. 1995:325-328.

27. Jones SE, Jomary C. Clusterin. Int J Biochem Cell Biol. 2002;34:427-431. 
28. Shannan B, Seifert M, Leskov K, et al. Challenge and promise: roles for clusterin in pathogenesis, progression and therapy of cancer. Cell Death Differ. 2006;13(1):12-19.

29. Pucci S, Bonanno E, Pichiorri F, Angeloni C, Spagnoli LG. Modulation of different clusterin isoforms in human colon tumorigenesis. Oncogene. 2004;23(13):2298-2304. doi:10.1038/sj.onc.1207404

30. Frazzi R, Casali B, lori M, Nicoli D, Mammi C, Merli F. Increase in clusterin forms part of the stress response in Hodgkin's lymphoma. Int J Oncol. 2011;38:677-684.

31. Saffer H, Wahed A, Rassidakis GZ, Medeiros LJ. Clusterin expression in malignant lymphomas: a survey of 266 cases. Mod Pathol. 2002;15(11):1221-1226.

32. Steinberg J, Oyasu R, Lang S, et al. Intracellular Grade Levels of SGP-2 Correlate with Tumor in Prostate. Clin Cancer Res. 1997;3(October):1707-1711.

33. Redondo M, Villar E, Torres-mun J, Tellez T, Morell M, Petito CK. Overexpression of Clusterin in Human Breast Carcinoma. Am J Pathol. 2000;157(2):393-399.

34. Yom CHAK, Woo H, Min SUNY, Kang SOY, Kim HEES. Clusterin Overexpression and Relapse-free Survival in Breast Cancer. 2009;3912:3909-3912.

35. Krüger S, Ola V, Fischer D, Feller AC, Friedrich M. Prognostic significance of clusterin immunoreactivity in breast cancer. Neoplasia. 2007;54(1):46-50.

36. Guo W, Ma X, Xue C, et al. Serum Clusterin as a Tumor Marker and Prognostic Factor for Patients with Esophageal Cancer. Dis Markers. 2014;2014.

37. Nafee AM, Pasha HF, Abd SM, Aal E, Mostafa NA. Clinical significance of serum clusterin as a biomarker for evaluating diagnosis and metastasis potential of viral - related hepatocellular carcinoma. Clin Biochem. 2012;45:1070-1074.

38. Rodriguez-Pineiro AM, Paez de la Cadena M, Lopez-Saco A, Rodriguez-Berrocal FJ. Differential Expression of Serum Clusterin Isoforms in Colorectal Cancer *. Mol Cell Proteomics. 2006;5:1647-1657.

39. Trougakos IP, Djeu JY, Gonos ES, Boothman DA. Advances and challenges in basic and translational research on clusterin. Cancer Res. 2009;69(2):403-406. doi:10.1158/0008-5472.CAN-08-2912

40. Bettuzzi S, Davalli P, Davoli S, et al. Genetic inactivation of ApoJ/clusterin: Effects on prostate tumourigenesis and metastatic spread. Oncogene. 2009;28(49):4344-4352. doi:10.1038/onc.2009.286

41. Wellmann A, Thieblemont C, Pittaluga S, et al. Detection of differentially expressed genes in lymphomas using cDNA arrays: identification of clusterin as a new diagnostic marker for anaplastic large-cell lymphomas. Blood. 2000;96(2):398-404.

42. Lae ME, Ahmed I, Macon WR. Clusterin Is Widely Expressed in Systemic Anaplastic Large Cell Lymphoma but Fails to Differentiate Primary From Secondary Cutaneous Anaplastic. Am J Clin Pathol.

2002;118:773-779.

43. Nascimento AF, Pinkus JL, Pinkus GS. Clusterin, a Marker for Anaplastic Large Cell Lymphoma Immunohistochemical Profile in Hematopoietic and Nonhematopoietic Malignant Neoplasms. Am J Clin Pathol. 2004;121:709-717. doi:10.1309/GQ2RLNDWLB9WY6UU

44. Atherton MJ, Braceland $\mathrm{M}$, Fontaine $\mathrm{S}$, et al. Changes in the serum proteome of canine lymphoma identified by electrophoresis and mass spectrometry. Vet J. 2013;196(3):320-324.

45. Owen L. TNM Classification of tumours in domestic animals. World Heal Organ. 1980:1-52.

46. Vail DM, Michels GM, Khanna C, Selting KA, London CA. Response evaluation criteria for peripheral nodal lymphoma in dogs (v1.0)-a veterinary cooperative oncology group (VCOG) consensus document. Vet Comp Oncol. 2010;8(1):28-37. doi:10.1111/j.1476-5829.2009.00200.x

47. Shafie INF, Anderson TJ, Penderis J, Eckersall PD, Mclaughlin M. A protocol for the management of canine cerebrospinal fluid for the proteomic assessment of putative biomarkers. 2013;197:836-841.

48. Shafie INF, McLaughlin M, Burchmore R, et al. The chaperone protein clusterin may serve as a cerebrospinal fluid biomarker for chronic spinal cord disorders in the dog. Cell Stress Chaperones. 2014;19(3):311-320. doi:10.1007/s12192-013-0457-4

49. Schneider CA, Rasband WS, Eliceiri KW. HISTORICAL commentary NIH Image to ImageJ : 25 years of image analysis. 2012;9(7):671-675.

50. Caccamo AE, Scaltriti M, Caporali A, et al. Cell detachment and apoptosis induction of immortalized human prostate epithelial cells are associated with early accumulation of a $45 \mathrm{kDa}$ nuclear isoform of clusterin. Biochem J. 2004;382(1):157-168. doi:10.1042/BJ20040158

51. Leskov KS, Klokov DY, Li J, Kinsella TJ, Boothman DA. Synthesis and functional analyses of nuclear clusterin, a cell death protein. J Biol Chem. 2003;278(13):11590-11600. doi:10.1074/jbc.M209233200

52. Wyatt A, Yerbury J, Poon S, Dabbs R, Wilson M. The Chaperone Action of Clusterin and Its Putative Role in Quality Control of Extracellular Protein Folding. In: Advances in Cancer Research. ; 2009:89-114. doi:10.1016/S0065-230X(09)04006-8 
53. Wilson MR, Zoubeidi A. Clusterin as a therapeutic target. Expert Opin Ther Targets. 2017;21(2):201-213. doi:10.1080/14728222.2017.1267142

54. Humphreys DT, Carver JA, Easterbrook-smith SB, Wilson MR. Clusterin Has Chaperone-like Activity Similar to That of Small Heat Shock Proteins *. J Biol Chem. 1999;274(11):6875-6881.

55. Scaltriti M, Brausi M, Amorosi A, et al. CLUSTERIN ( SGP-2, ApoJ ) EXPRESSION IS DOWNREGULATED IN LOW- AND HIGH-GRADE HUMAN PROSTATE CANCER. Int J Cancer. 2004;108:23-30. doi:10.1002/ijc.11496

56. Rizzi F, Bettuzzi S. Targeting clusterin in prostate cancer. J Physiol Pharmacol. 2008;59(SUPPL. 9):265274. doi:10.1111/j.1365-2036.2011.04905.x

57. Kang Y, Hong S, Lee H, Kim W. Overexpression of Clusterin in Human Hepatocellular Carcinoma. Hum Pathol. 2004;35:1340-1346. doi:10.1016/j.humpath.2004.07.021

58. Coletta M, Frazzi R, Rizzi F, et al. Clusterin Expression and Localization Are Affected by Rituximab and Doxorubicin Treatment in Non-Hodgkin Lymphoma Cells and B Lymphocytes. Blood. 2012;(1318).

59. Sueiro FAR, Alessi AC, Vassallo J. Canine lymphomas: A morphological and immunohistochemical study of 55 cases, with observations on p53 immunoexpression. J Comp Pathol. 2004;131(2-3):207-213. doi:10.1016/j.jcpa.2004.04.002

60. Vezzali E, Parodi A., Marcato P., Bettini G. Histopathologic classification of 171 cases of canine and feline non-Hodgkin lymphoma according to the WHO - Vezzali - 2009 - Veterinary and Comparative Oncology Wiley Online Library. Vet Comp Oncol. 2010;8(1):38-49.

61. Trougakos IP, Petropoulou C, Franceschi C, Gonos ES. Reduced Expression Levels of the Senescence Biomarker Clusterin / Apolipoprotein J in Lymphocytes from Healthy Centernarians. Ann N Y Acad Sci. 2006;300:294-300. doi:10.1196/annals.1354.039

62. Mondello C, Petropoulou C, Monti D, Gonos ES, Franceschi C, Nuzzo F. Telomere Length in Fibroblasts and Blood Cells from Healthy Centenarians. 1999;242:234-242. 


\section{Figure titles and legends}

Figure 1): A western blot analysis of serum CLU, in samples of varying protein concentrations.

Confirming antibody specificity, showing the CLU protein at approx. 37kDa in the presence of the primary anticlusterin antibody but not with the secondary antibody only.

The position of the molecular weight marker (Mk), annotated at 48 and $37 k D a$.

Figure 2): Western blot analysis of serum CLU.

i) Western blot of serum CLU in dogs with MLSA pre-treatment ( $n=12, A 1-A 12)$ and healthy controls ( $n=12$, C1-C12).

ii) Western blot of serum CLU in dogs with MLSA in CR ( $n=12, B 1-B 12)$ and healthy controls $(n=12$, C1-C12).

iii) Western blot of serum CLU in dogs with MLSA pre-treatment ( $n=12, A 1-A 12)$ and unrelated dogs with MLSA in $C R(n=12, B 1-B 12)$.

Figure 3): Serum CLU levels, from western blot analysis, comparing dogs with MLSA pre-treatment, unrelated dogs with MLSA in CR and healthy controls.

Vertical scatter graphs showing data distribution from each western blot:

i) Comparing dogs with MLSA pre-treatment $(A, n=12)$ with healthy controls $(C, n=12)$.

ii) Comparing dogs with MLSA in $C R(B, n=12)$ and healthy controls $(C, n=12)$.

iii) Comparing dogs with MLSA pre-treatment $(A, n=12)$ with unrelated dogs with MLSA in CR (B, $n=12)$.

Data presented with median and interquartile range.

No significant difference in CLU between any of the three cohorts.

Figure 4): Serum CLU concentrations, from ELISA analysis, comparing dogs with MLSA pre-treatment, unrelated dogs in CR and healthy controls.

Vertical scatter graphs showing data distribution from ELISA: comparing dogs with MLSA pre-treatment ( $A$, $n=12)$, unrelated dogs with MLSA in $C R(B, n=12)$ and healthy controls $(C, n=12)$.

Data presented with median and interquartile range.

ANOVA revealed significant difference in CLU between the three cohorts. Serum CLU concentration was significantly higher in the controls in comparison to both MLSA pre-treatment and in CR (Bonferroni comparison $p<0.05)$ There was no significant difference between dogs with MLSA prior to treatment and in CR. $* * * p<0.001$

$* p<0.05$

Figure 5): Serum CLU concentrations, from ELISA analysis, comparing serum CLU in dogs with MLSA pretreatment $(n=18)$, and at time of $C R(n=18)$; paired samples from the same individuals.

i) Vertical scatter graphs showing data distribution from each ELISA: comparing CLU in dogs with MLSA pre-treatment and at time of CR. Data presented with median and interquartile range.

ii) Second line graph documenting no significant trend for changes in individual CLU concentration following treatment and achieving $C R$.

Statistical analysis revealed no significant difference in individual serum CLU concentrations in dogs with MLSA following treatment.

Figure 6): Serum CLU concentrations, from ELISA analysis, comparing dogs with MLSA pre-treatment $(n=18)$ to healthy controls $(n=18)$; age matched samples.

Vertical scatter graphs showing data distribution from ELISA: comparing dogs with MLSA pre-treatment and healthy control dogs. Data presented with median and interquartile range. 
Statistical analysis revealed significant difference in CLU between the two cohorts, with serum CLU concentration significantly higher $(p<0.05)$ in healthy controls in comparison to dogs with MLSA prior to treatment.

$* * * p<0.001$ 
Table 1) Signalment of sample group one, consisting of dogs with MLSA pre-treatment ( $n=12$, cohort A), unrelated dogs with MLSA in CR ( $n=12$, cohort B) and healthy controls ( $n=12$, cohort $C)$.

\begin{tabular}{|c|c|c|c|c|}
\hline & $\begin{array}{c}\text { Pre Treatment } \\
M L S A \\
(A, n=12) \\
\end{array}$ & $\begin{array}{c}C R \\
M L S A \\
(B, n=12) \\
\end{array}$ & $\begin{array}{l}\text { Control } \\
(C, n=12)\end{array}$ & $p$ values \\
\hline $\begin{array}{l}\text { Median Age (years) } \\
\text { Range }\end{array}$ & $\begin{array}{l}8 \\
5-12\end{array}$ & $\begin{array}{l}7.5 \\
4-12 \\
\end{array}$ & $\begin{array}{l}4 \\
1-7 \\
\end{array}$ & $\begin{array}{l}\text { ANOVA } \\
p<0.05\end{array}$ \\
\hline $\begin{array}{l}\text { Sex: } \\
\text { Male entire } \\
\text { Male neutered } \\
\text { Female entire } \\
\text { Female neutered }\end{array}$ & $\begin{array}{l}4 \\
5 \\
3 \\
0\end{array}$ & $\begin{array}{l}3 \\
4 \\
0 \\
5\end{array}$ & $\begin{array}{l}3 \\
4 \\
1 \\
4\end{array}$ & $\begin{array}{l}\text { Chi squared } \\
p>0.05\end{array}$ \\
\hline $\begin{array}{l}\text { Stage: } \\
\text { II } \\
\text { III } \\
\text { IV } \\
\text { V }\end{array}$ & $\begin{array}{l}0 \\
0 \\
4 \\
8 \\
\end{array}$ & $\begin{array}{l}1 \\
3 \\
6 \\
2 \\
\end{array}$ & $\mathrm{~N} / \mathrm{a}$ & $\begin{array}{c}\text { Chi squared } \\
p<0.05\end{array}$ \\
\hline $\begin{array}{l}\text { Substage: } \\
\text { a } \\
\text { b }\end{array}$ & $\begin{array}{l}3 \\
9\end{array}$ & $\begin{array}{l}5 \\
7\end{array}$ & $\mathrm{~N} / \mathrm{a}$ & $\begin{array}{c}\text { Fisher's exact } \\
\quad p>0.05\end{array}$ \\
\hline $\begin{array}{l}\text { Immunophenotype: } \\
\text { B } \\
\text { T }\end{array}$ & $\begin{array}{l}7 \\
1 \\
\end{array}$ & $\begin{array}{l}10 \\
0\end{array}$ & N/a & $\begin{array}{c}\text { Fisher's exact } \\
p>0.05\end{array}$ \\
\hline $\begin{array}{l}\text { Breed: } \\
\text { Beagle } \\
\text { Border collie } \\
\text { Border terrier } \\
\text { Boxer } \\
\text { Cairn Terrier } \\
\text { Cavalier King Charles spaniel } \\
\text { Cocker spaniel } \\
\text { Crossbreed } \\
\text { Dachshund } \\
\text { Doberman pinscher } \\
\text { Flat coated retriever } \\
\text { German shepherd } \\
\text { Golden retriever } \\
\text { Gordon setter } \\
\text { Greyhound } \\
\text { Hungarian vizsla } \\
\text { Jack Russel terrier } \\
\text { Labrador retriever } \\
\text { Tibetan terrier } \\
\text { Whinnet }\end{array}$ & $\begin{array}{l}0 \\
3 \\
1 \\
2 \\
1 \\
1 \\
0 \\
1 \\
0 \\
0 \\
0 \\
0 \\
0 \\
1 \\
0 \\
0 \\
0 \\
2 \\
0 \\
0\end{array}$ & $\begin{array}{l}1 \\
2 \\
0 \\
0 \\
0 \\
0 \\
1 \\
1 \\
1 \\
0 \\
0 \\
1 \\
1 \\
0 \\
0 \\
1 \\
1 \\
0 \\
1 \\
1\end{array}$ & $\begin{array}{l}0 \\
0 \\
0 \\
0 \\
0 \\
0 \\
0 \\
1 \\
0 \\
1 \\
1 \\
2 \\
3 \\
0 \\
1 \\
0 \\
0 \\
3 \\
0 \\
0\end{array}$ & - \\
\hline
\end{tabular}


Table 2) Signalment of sample group two, consisting of dogs with MLSA pre-treatment $(n=18)$, and at time of $C R(n=18)$; paired samples from the same individuals.

\begin{tabular}{|c|c|}
\hline & Paired Samples $(n=18)$ \\
\hline $\begin{array}{l}\text { Median Age (years) } \\
\text { Range }\end{array}$ & $\begin{array}{l}8.3 \\
5-14\end{array}$ \\
\hline $\begin{array}{l}\text { Sex: } \\
\text { Male entire } \\
\text { Male neutered } \\
\text { Female entire } \\
\text { Female neutered }\end{array}$ & $\begin{array}{l}4 \\
5 \\
2 \\
7\end{array}$ \\
\hline $\begin{array}{l}\text { Stage: } \\
\text { II } \\
\text { III } \\
\text { IV } \\
\text { V }\end{array}$ & $\begin{array}{l}0 \\
3 \\
9 \\
6\end{array}$ \\
\hline $\begin{array}{l}\text { Substage: } \\
\text { a } \\
\text { b }\end{array}$ & $\begin{array}{l}11 \\
7\end{array}$ \\
\hline $\begin{array}{l}\text { Immunophenotype: } \\
\text { B } \\
T\end{array}$ & $\begin{array}{l}10 \\
2\end{array}$ \\
\hline $\begin{array}{l}\text { Breed: } \\
\text { Border collie } \\
\text { Cocker spaniel } \\
\text { Crossbreed } \\
\text { German shepherd } \\
\text { Golden retriever } \\
\text { Jack Russel terrier } \\
\text { Labrador retriever } \\
\text { Parsons terrier } \\
\text { Shih Tzu } \\
\text { Spinoni } \\
\text { Tibetan terrier } \\
\text { West Highland White terrier } \\
\text { Yorkshire terrier }\end{array}$ & $\begin{array}{l}3 \\
1 \\
1 \\
1 \\
3 \\
1 \\
2 \\
1 \\
1 \\
1 \\
1 \\
1 \\
1\end{array}$ \\
\hline
\end{tabular}


Table 3) Signalment of sample group three, consisting of dogs with MLSA pre-treatment $(n=18)$ and healthy controls $(n=18)$; age matched sample cohorts.

\begin{tabular}{|c|c|c|c|}
\hline & Pre-treatment $(n=18)$ & Controls $(n=18)$ & $p$ values \\
\hline $\begin{array}{l}\text { Median Age (years) } \\
\text { Range }\end{array}$ & $\begin{array}{c}6 \\
3-7 \\
\end{array}$ & $\begin{array}{c}5 \\
4-7 \\
\end{array}$ & $\begin{array}{l}\text { Mann Whitney U Test } \\
p>0.05\end{array}$ \\
\hline $\begin{array}{l}\text { Sex: } \\
\text { Male entire } \\
\text { Male neutered } \\
\text { Female entire } \\
\text { Female neutered }\end{array}$ & $\begin{array}{l}4 \\
8 \\
1 \\
5\end{array}$ & $\begin{array}{l}4 \\
5 \\
1 \\
8 \\
\end{array}$ & $\begin{array}{l}\text { Chi squared } \\
\text { Fisher's exact } \\
p>0.05\end{array}$ \\
\hline $\begin{array}{l}\text { Stage: } \\
\text { II } \\
\text { III } \\
\text { IV } \\
\text { V } \\
\end{array}$ & $\begin{array}{l}0 \\
7 \\
8 \\
3 \\
\end{array}$ & N/a & - \\
\hline $\begin{array}{l}\text { Substage: } \\
\text { a } \\
\text { b }\end{array}$ & $\begin{array}{c}7 \\
11\end{array}$ & $\mathrm{~N} / \mathrm{a}$ & - \\
\hline $\begin{array}{l}\text { Immunophenotype: } \\
\text { B } \\
T\end{array}$ & $\begin{array}{l}5 \\
9 \\
\end{array}$ & $\mathrm{~N} / \mathrm{a}$ & - \\
\hline $\begin{array}{l}\text { Breed: } \\
\text { Bernese Mountain dog } \\
\text { Border collie } \\
\text { Boxer } \\
\text { Bullmastiff } \\
\text { Cocker spaniel } \\
\text { Crossbreed } \\
\text { Doberman } \\
\text { Dogue de Bordeaux } \\
\text { Flat-coated retriever } \\
\text { Golden retriever } \\
\text { Greyhound } \\
\text { Jack Russel terrier } \\
\text { Labrador retriever } \\
\text { Lurcher } \\
\text { Shetland sheepdog } \\
\text { Springer spaniel } \\
\text { Tibetan terrier } \\
\text { Weimeraner }\end{array}$ & $\begin{array}{l}1 \\
3 \\
1 \\
1 \\
2 \\
1 \\
0 \\
1 \\
1 \\
3 \\
0 \\
1 \\
0 \\
1 \\
1 \\
0 \\
1 \\
0\end{array}$ & $\begin{array}{l}0 \\
0 \\
0 \\
0 \\
0 \\
1 \\
1 \\
0 \\
0 \\
2 \\
8 \\
0 \\
4 \\
0 \\
0 \\
1 \\
0 \\
1\end{array}$ & - \\
\hline
\end{tabular}


Figure 1

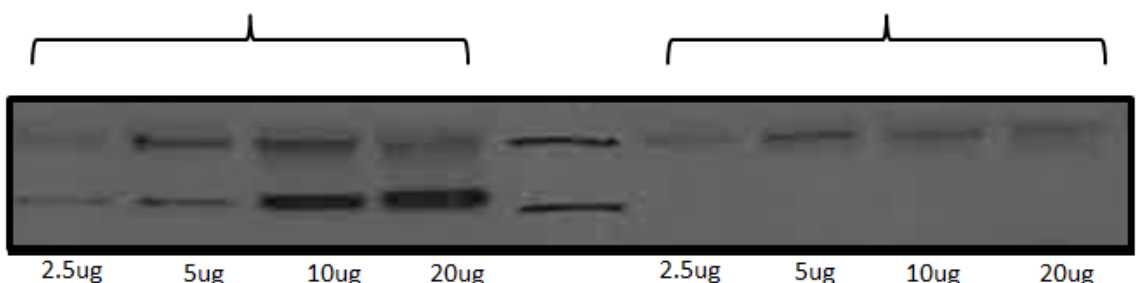

$37 \mathrm{kDa}$

Figure 2.i
A1 C1 A2 C2
A3 C3
A4 C4
A5 C5 A6 C6
A7 $\quad$ C7
A8 C8
$\begin{array}{llllll}\text { A9 } & \text { C9 } & \text { A10 } & \text { C10 } & \text { A11 } & \text { C11 }\end{array}$
A12 C12

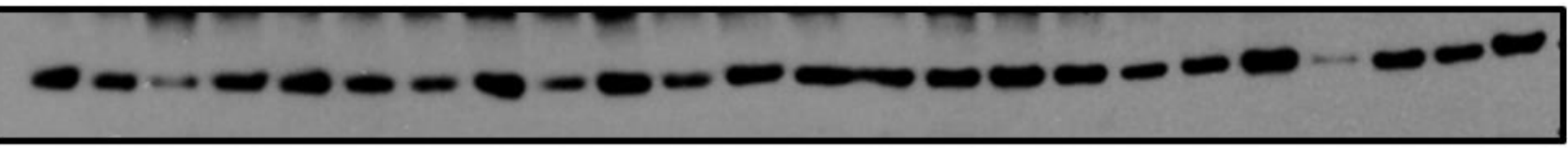

Figure 2.ii

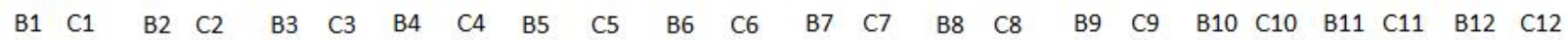

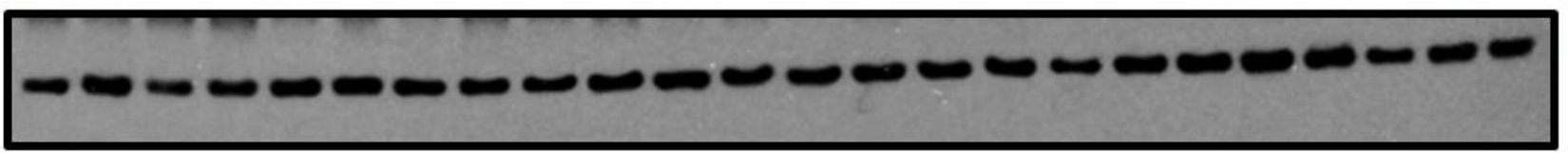

Figure 2.iii

$\begin{array}{lllllllllllllllllllllllllllll}\text { A1 } & \text { B1 } & \text { A2 } & \text { B2 } & \text { A3 } & \text { B3 } & \text { A4 } & \text { B4 } & \text { A5 } & \text { B5 } & \text { A6 } & \text { B6 } & \text { A7 } & \text { B7 } & \text { A } & \text { B8 } & \text { A9 } & \text { B9 } & \text { A10 } & \text { B10 } & \text { A11 } & \text { B11 } & \text { A12 } & \text { B12 }\end{array}$ 
Figure 3.i

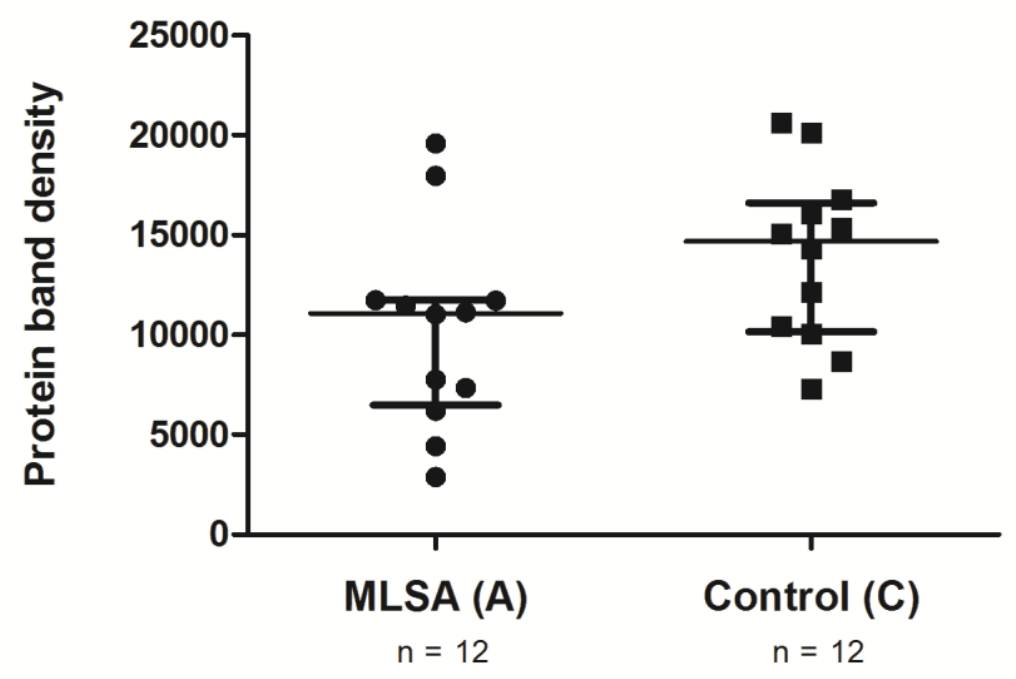

Figure 3.ii

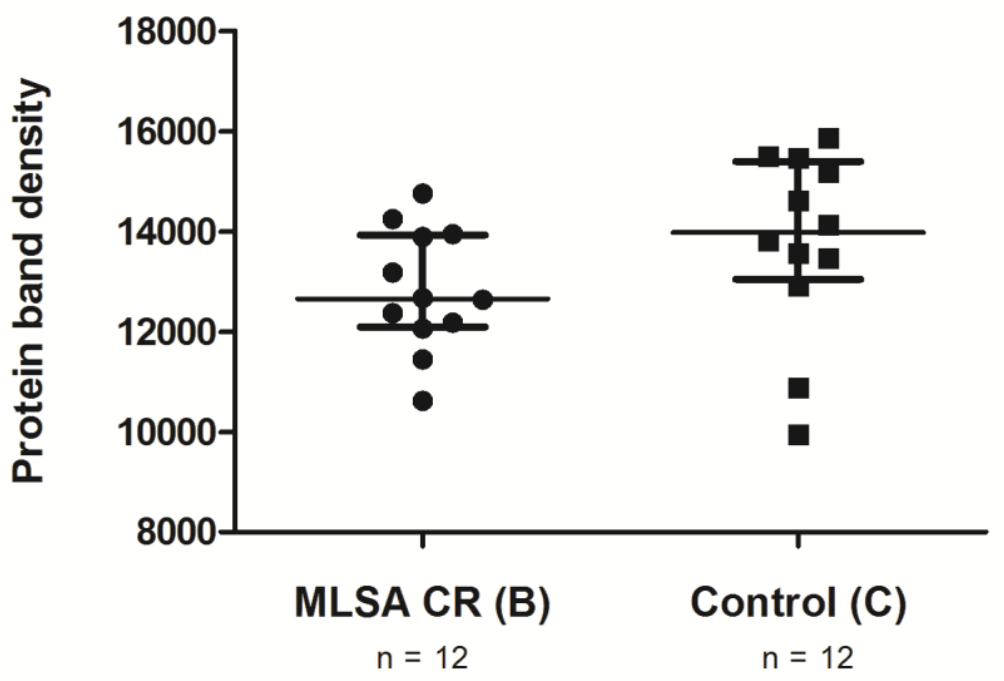

Figure 3.iii

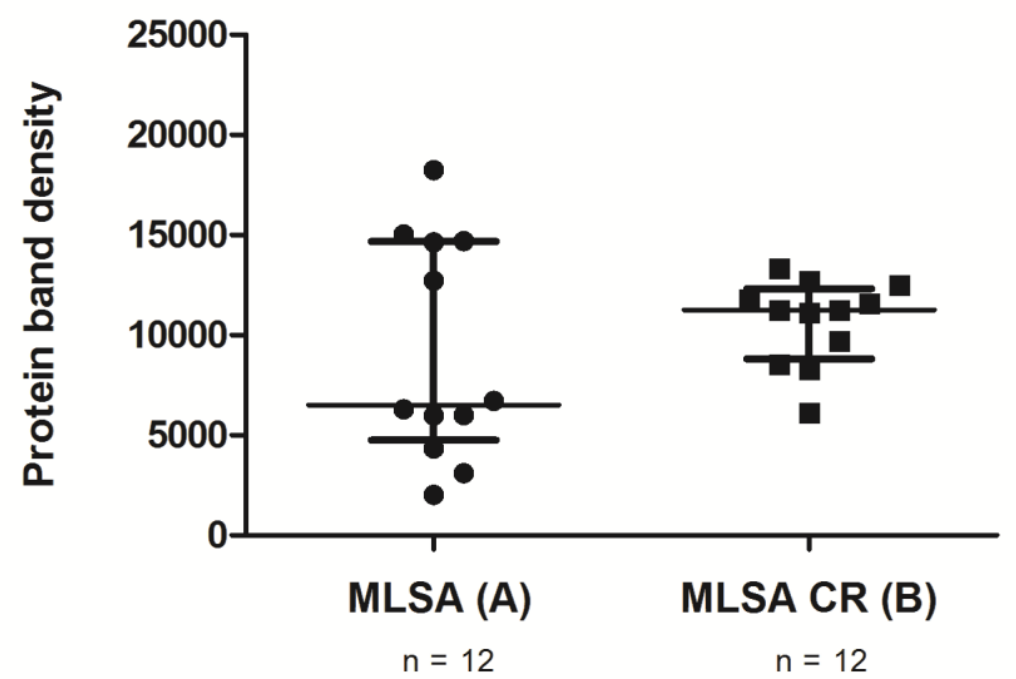


Figure 5.i

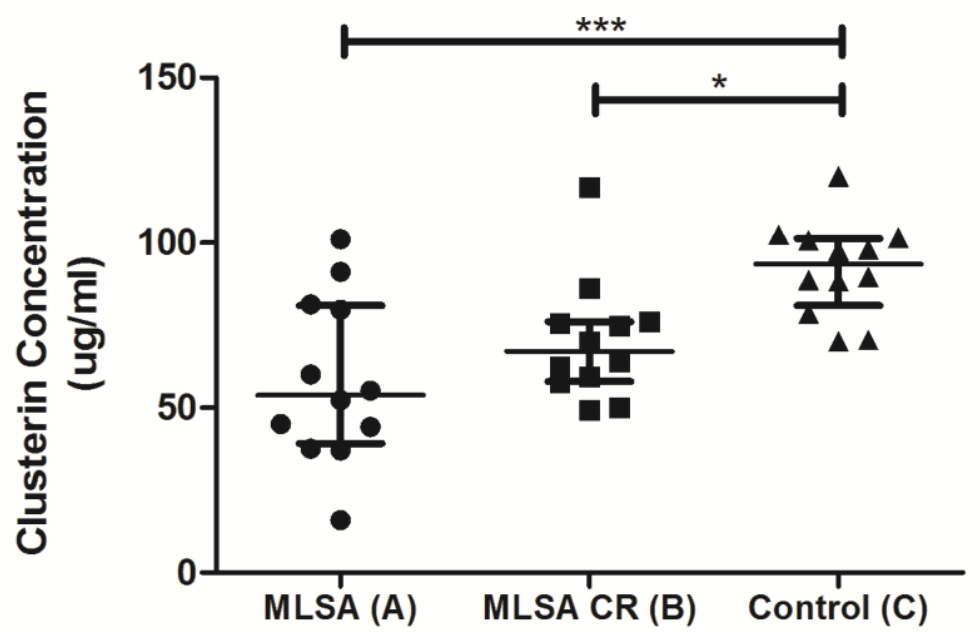

Figure 5.ii

$$
\mathrm{n}=12 \mathrm{n}=12 \quad \mathrm{n}=12
$$
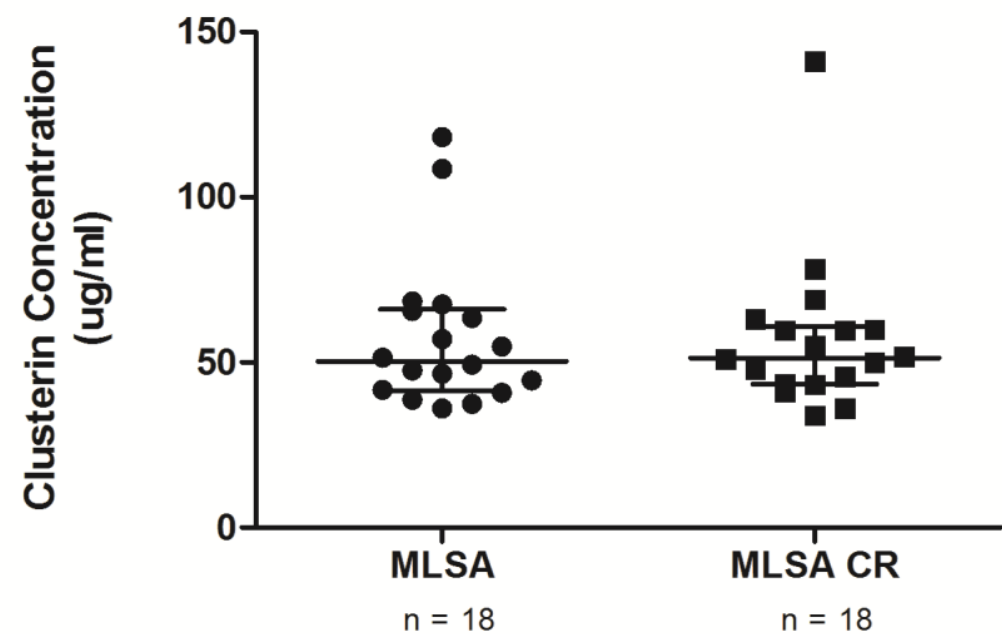

Figure 5.iii

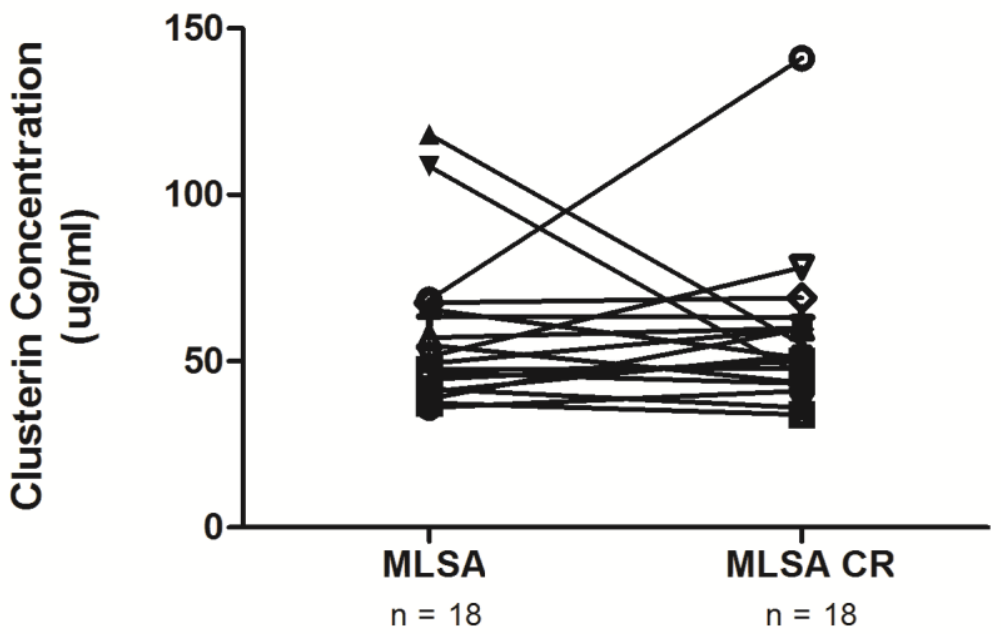


Figure 6.

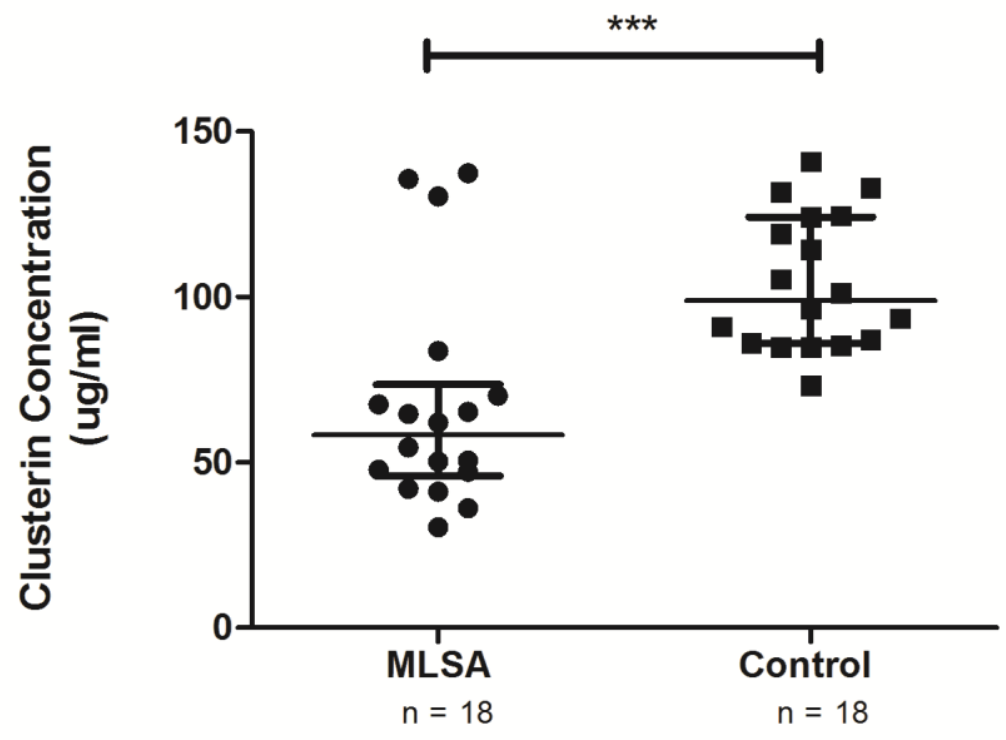

